\title{
Compatibilidade Sexual e Vegetativa do Complexo Glomerella- Colletotrichum Associado a Sementes de Algodão
}

\author{
Maria G. Roca M. ${ }^{1}$, José da C. Machado ${ }^{1}$, Maria das G. G. C. Vieira $^{1}$, Lisete C. Davide ${ }^{1}$ \\ \& Mario L. de M. Rocha ${ }^{2}$
}

${ }^{1}$ Universidade Federal de Lavras, DFP, Cx. Postal 37, CEP 37200-000, Lavras, MG, Fax: (35) 3829-1283, e-mail: machado@ufla; ${ }^{2}$ Secretaria de Agricultura, Indústria e Comércio de Cáceres, MT

(Aceito para publicação em 24/09/2003)

Autor para correspondência: José da Cruz Machado

ROCA M., M.G., MACHADO, J.D.C., VIEIRA, M.G.C., DAVIDE, L.C. \& ROCHA, M.L. Compatibilidade sexual e vegetativa do complexo Glomerella-Colletotrichum associado a sementes de algodão. Fitopatologia Brasileira 29:016-020. 2004.

\section{RESUMO}

Colletotrichum gossypii (Cg) (Glomerella gossipii) e Colletotrichum gossypii var. cephalosporioides $(\mathrm{Cgc})$ são agentes etiológicos da antracnose e da ramulose no algodoeiro (Gossypium hirsutum). Ambos os patógenos são encontrados na forma mitospórica na natureza e a diferenciação entre eles é feita principalmente a partir dos sintomas das doenças causadas. $\mathrm{O}$ presente trabalho foi realizado com o objetivo de verificar a ocorrência de reações de compatibilidade sexual e incompatibilidade vegetativa entre e dentro de isolados de $\mathrm{Cg}$ e Cgc e avaliar alguns aspectos citológicos das formas de esporulação.
Pelos resultados, observou-se existência de grande variabilidade dentro dessa espécie. Os conídios diferiram em tamanho em todos os isolados, sendo encontrados conídios bi- e trinucleados. Em cultura, nas áreas de contato (entre as hifas), foram observadas reações de incompatibilidade vegetativa tanto entre quanto dentro dos isolados. Em apenas um dos isolados avaliados ocorreu reprodução sexuada de forma espontânea, sugerindo comportamento homotálico.

Palavras-chave adicionais: anastomose, antracnose, ramulose, citogenética, reprodução sexual.

\section{ABSTRACT}

Sexual and vegetative compatibility of Glomerella-Colletotrichum complex associated with cotton seeds

Colletotrichum gossypii (Cg) (Glomerella gossypii) and Colletotrichum gossypii var. cephalosporioides $(\mathrm{Cgc})$ are pathogens of anthracnose and ramulose in cotton (Gossypium hirsutum). These pathogens cause typical and distinct symptoms in susceptible plants and they occur in the mitosporic phase of hosts in nature. This work aimed to check the occurrence of sexual and vegetative incompatibility

\section{INTRODUÇÃO}

Glomerella gossypii Edgerton foi descrita pela primeira vez em isolados a partir de plantas de algodoeiro (Gossypium hirsutum L.) em 1908 (Edgerton, 1909). Posteriores descrições não foram encontradas na literatura. $\mathrm{Na}$ natureza, sua ocorrência se dá na forma mitospórica, sendo citada como Colletotrichum gossypii South. (Cg), quando causa antracnose e Colletotrichum gossypii var. cephalosporioides (Costa \& Fraga) (Cgc) quando causa a ramulose no algodoeiro. Ambos os fungos são semelhantes morfologicamente, e a diferenciação entre eles baseia-se principalmente nos sintomas da doença causada nas plantas de algodoeiro e/ou com o uso de marcadores moleculares (Tanaka et al., 1996; Cia \& Salgado, 1997; Silva-Mann et al., 2002).

A ampliação da variabilidade genética para a grande maioria dos seres vivos ocorre através da reprodução sexual (forma meiospórica no caso de fungos), entretanto em $20 \%$ das espécies de fungos identificadas, este tipo de reprodução reactions between and within isolates of $\mathrm{Cg}$ and $\mathrm{Cgc}$, and also to study some cytological aspects involving the sporulation process. A large variability was observed within these pathogens. Conidia were differentiated in size in all isolates and some presented two or three nuclei. Vegetative incompatibility between and within isolates took place at the contact lines of mycelia growth. Spontaneous sexual reproduction was found in only one isolate, indicating the homothallic behavior of this isolate. ainda não foi descrito (Carlile et al., 2001); nesses casos, descrições mais detalhadas da forma assexual são necessárias. Em áreas de encontro das colônias, de um mesmo isolado ou entre diferentes isolados, podem ser verificadas a ocorrência de compatibilidade sexual (reprodução sexual) e compatibilidade ou incompatibilidade vegetativa (Glass et al., 2000). Anastomoses de hifas permitem a troca do conteúdo celular entre indivíduos diferentes sendo este evento requerido nas reações de compatibilidade, início da reprodução sexual, formação de heterocarions, ciclo parasexual e a distribuição de nutrientes no micélio/colônia (Glass et al., 2000; Hickey et al., 2002).

Com base em descrição genética, os fungos são ditos antagônicos quando ocorrem distintamente heterocários sexuais e vegetativos na região de contato entre hifas dos diferentes isolados (Alexopoulos et al., 1996). A reprodução sexual pode ocorrer tanto entre isolados heterotálicos como entre isolados homotálicos (Robertson et al., 1998). Os isolados que, durante a fase mitospórica, são compatíveis vegetati- 
Compatibilidade sexual e vegetativa do complexo Glomerella-Colletotrichum associado...

vamente com outros, são freqüentemente incluídos em um mesmo grupo de compatibilidade vegetativa (Leslie, 1993), caso contrário apresentam incompatibilidade vegetativa (Saupe, 2000). Quando não há formação de peritécios, os quais confirmam a ocorrência de reprodução sexuada (compatibilidade sexual), existem características do comportamento vegetativo dos isolados, como produção de enzimas, compatibilidade ou incompatibilidade vegetativa, que permitem agrupá-los (Molnar et al., 1990; Hornet al., 2002). Além disso, é possível verificar se ocorre algum processo durante a reprodução assexuada, como heterocariose, que ajude a explicar a variabilidade genética (Chacko et al., 1994; Glass et al., 2000).

Este trabalho foi realizado com o objetivo de caracterizar áreas específicas de crescimento micelial e descrever as formas de esporulação dos fungos componentes do complexo Colletotrichum associado ao algodoeiro, e assim contribuir para esclarecer a existência de compatibilidades sexuais e/ou incompatibilidades vegetativas em meio de cultura, entre e dentro de isolados de C. gossypii e C. g. var. cephalosporioides.

\section{MATERIAIS E MÉTODOS}

\section{Isolados fúngicos}

Foram utilizados diferentes isolados de C. gossypii e C. gossypii var. cephalosporioides mantidos na micoteca do Laboratório de Patologia de Sementes do Departamento de Fitopatologia na Universidade Federal de Lavras (UFLA) (Tabela 1). Os isolados foram repicados em placas com BDA e mantidos em condições controladas de temperatura, umidade e iluminação (Silva-Mannet al., 2002).

\section{Preparações Citológicas}

Foram realizadas preparações citológicas da forma meiospórica, mitospórica e de micélios em áreas específicas de crescimento para avaliação do número de núcleos. Os núcleos foram corados em células previamente fixadas em solução de etanol: ácido acético (3:1) e corados com carmin-orceína propiônica $2 \%$, camin-orceína acética $2 \%$ ou Giemsa $2 \%$, em intervalos variáveis dependendo da estrutura a ser corada, segundo Roca (1997). Os excessos de fixador e corante foram removidos com lavagens em tampão fosfato, pH 7,8 (Roca, 1997).

As medições dos peritécios e do número de ascos e ascósporos foram realizadas em lâminas montadas com água glicerinada $50 \%$. Foram medidos dez peritécios provenientes de três placas diferentes, tomados aleatoriamente. O número de ascos foi determinado em 24 peritécios, tendo sido avaliadas três lâminas obtidas de três placas diferentes. Foram medidos 24 ascósporos (análises prévias mostraram que se trata de um tamanho de amostra suficiente para representar a variabilidade apresentada, dados näo publicados), em três lâminas obtidas de três placas diferentes.

O comprimento e diâmetro dos conídios e clamidosporos foram medidos em lâminas microscópicas montadas com água glicerinada $50 \%$, considerando-se duas épocas distintas, sete- dez dias e 22-25 dias de idade da cultura. Foram medidos 24 conídios, em três lâminas diferentes, obtidas de três placas diferentes. Em amostras de mesmo tamanho foram realizadas contagens do número de núcleos/conídio. Neste caso, os conídios foram fixados em carmin-acético por $24 \mathrm{~h}$ e corados com carmin-orceína acética $2 \%$, em períodos de 6 a 24 h, de acordo com a metodologia apresentada por Roca (1997), modificada em função dos diferentes isolados.

A avaliação do comprimento e largura de ascósporos, conídios e clamidosporos foi realizada em delineamento inteiramente casualizado e para as análises de variância utilizouse o programa MSTATC 1.41.

Todas as medições foram realizadas com o auxílio de uma ocular milimetrada OSM em microscópio de luz, modelo LABPHOT da CANON.

\section{Avaliação da compatibilidade sexual e incompatibilidade vegetativa}

Pareamentos de colônias, entre e dentro de isolados de C. gossypii e C. gossypii var. cephalosporioides foram realizados em todas as combinações possíveis. Três discos de aproximadamente $0,5 \mathrm{~cm}$ de diâmetro de cultura foram retirados de uma placa de Petri e repicados para três placas com BDA, foram colocados distantes a $5 \mathrm{~cm}$ uns dos outros, combinados dois a dois obtendo todas as combinações possíveis. Duas das repetições foram conduzidas em BDA com papel celofane, para facilitar a manipulação e preparação das lâminas de microscopia e uma terceira sem celofane como controle. $\mathrm{Na}$ região destes encontros foi observada a ocorrência de formação de peritécios ou de anastomose entre hifas ou morte celular nessa região do micélio. Os isolados que não apresentaram peritécios, foram avaliados microscopicamente em papel celofane. Para isso, fez-se a coloração com Giemsa 2\% (Roca, 1997) no próprio celofane na região de contato entre as hifas, até um máximo de quatro dias após a repicagem, bem como nos isolados crescidos de forma individual em papel celofane (controles). Para acompanhamento dos encontros, as colônias foram mantidas por 40 dias para verificar o crescimento posterior. A ocorrência de incompatibilidade vegetativa foi determinada a partir de avaliações visuais das regiões de encontro destas placas, aos 20 e 40 dias de idade das culturas.

As avaliações foram realizadas de acordo com o comportamento na área de encontro dos isolados. Estes foram então classificados em três grupos. No primeiro grupo foram considerados aqueles isolados que tiveram seu crescimento inibido pela presença das hifas de um outro isolado, não ocorrendo o encontro entre eles, e denominados incompatíveis vegetativamente. No segundo grupo foram incluídos isolados que cresceram normalmente sem nenhuma inibição pela presença de hifas do outro isolado, e foram denominados compatíveis vegetativamente. Finalmente, no terceiro grupo, foram incluídos os isolados que apresentaram comportamento intermediário, ou seja, tiveram seu crescimento afetado pela presença do outro isolado, porém não completamente inibido. O delineamento utilizado foi o inteiramente casualizado, sem realização de análises estatísticas. 


\section{M.G. Roca M. et al.}

\section{RESULTADOS E DISCUSSÃO}

\section{Compatibilidade sexual e fase meiospórica}

Entre os isolados estudados, apenas um, classificado como C. gossypii var. cephalosporioides, produziu peritécios de forma espontânea, sendo este o primeiro relato de ocorrência da forma sexuada entre isolados do agente etiológico da ramulose, posto que citações de G. gossypii na literatura dizem respeito ao agente etiológico da antracnose em algodoeiro (Edgerton, 1909). Os peritécios formaram-se em grupos, sobre uma massa de micélio de forma espalhada na placa, de cor marrom-escura, em forma de frascos cônicos, pilosos, gradualmente constritos em direção ao ápice, finalizando num rostrum curto (Figura 1a). O tamanho médio dos peritécios após o esmagamento para liberar os ascos e ascosporos na lâmina de vidro foi de $136,40 \pm 2,45 \mu \mathrm{m}$, sendo encontrados, em média, 22 ascos por peritécio. Os ascos apresentaram formato claviforme, sésseis, medindo 48,74 $\pm 5,13 \times 12,36 \pm 1,47 \mu \mathrm{m}$, corroborando com valores citados por Saccardo (1944). Foram produzidos oito ascósporos por asco (Figura 1b). Os ascósporos apresentavam-se hialinos, elípticos, ligeiramente curvos, medindo de $17,5 \pm 0,09 \times 5,97 \pm 0,95 \mu \mathrm{m}$, menores que os de G. cingulata (Sutton, 1992) (Figura 1b).

$\mathrm{Na}$ área de contato entre isolados que não produziram peritécios com isolados que produziram peritécios, observouse a formação de uma barreira de coloracão mais escura, sugerindo o início de formação de peritécios (Figura 1c).

Tendo sido observados em um único isolado, sua origem genética permite classificá-lo como homotálica, porém, cruzamentos entre um número maior de isolados permitiriam verificar a possibilidade de ocorrer heterotalismo (Cisar et al., 1994; Cisar \& TeBeest, 1999; Robertson et al., 1998).

\section{Incompatibilidade vegetativa e fase mitospórica}

Ambos, C. gossypii e C. gossypii var. cephalosporioides, esporularam produzindo conídios em acérvulos (ou esporodóquios) distribuídos em massas alaranjadas no meio de cultura. Alguns isolados produziram massas de conídios de forma sincrônica, formando anéis de crescimento no meio de cultura, mostrando regulação por um ciclo circardiano (Figura 1d) (Aronson et al., 1994). A organização celular desses acérvulos coincide com as características descritas na literatura (Tanaka et al., 1996). Verificou-se a formação de alças entre hifas, num período máximo de quatro dias de cultura. Enovelamento das hifas e crescimento de setas também foram observados, sendo algumas setas férteis. As alças formadas sugerem o início da formação dos acérvulos, semelhante à descrita para outras espécies do gênero Colletotrichum (Maiello, 1988).

Massas pretas de hifas enoveladas e melanizadas com grande quantidade de conídios no interior foram encontradas. Esses corpos mostraram-se bem resistentes, o que permitiria a sobrevivência por mais tempo em condições menos favoráveis.

Variações significativas $(P<0,005)$ foram observadas para tamanho de conídios, independente da época em que foi coletado, do material e do isolado. Os conídios de C. gossypii apresentaram em média $14,8 \pm 0,18 \mu \mathrm{m}$ de comprimento $\times 5,8 \pm 0,30$ $\mu \mathrm{m}$ de diâmetro, enquanto que para $C$. g. var.cephalosporioides estas medidas foram de $14,2 \pm 0,15 \times 4,9 \pm 0,09 \mu \mathrm{m}$ (Tabela 2). Esses dados também mostram que tamanhos diferentes não são devidos ao início do processo de germinação, mas, provavelmente, trata-se de características intrínsecas dos isolados (Tabela 2).

Atkinson (1891) relatou a ocorrência de conídios binucleados nesta espécie, porém citações atualizadas sobre esse tipo de ocorrência para C. gossypii var. cephalosporioides não foram encontradas. A ocorrência de conídios binucleados e trinucleados tem sido relatada também em outras espécies do gênero Colletotrichum (TeBeest et al., 1989; Mendes-Costa et al., 1998). A existência de conídios com vários núcleos, sem nenhuma característica aparente de emissão do tubo germinativo, poderia indicar herança durante o processo de conidiogênese (conidióforos ou setas férteis). Porém, os conídios não apresentam dormência aparentemente, o que leva

TABELA 1 - Isolados de Colletotrichum gossypii e C. gossypii var. cephalosporioides utilizados

\begin{tabular}{llll}
\hline \hline No. & Isolado & Espécie & Origem \\
\hline 01 & A-26 & Colletotrichum gossypii & Lavras-MG \\
02 & P-13 & C. gossypii & Lavras-MG \\
03 & C-12 & C. gossypii & Uberaba-MG, parcela 21 \\
04 & GC3 & C. gossypii & Lavras-MG \\
$01 \mathrm{c}$ & C.G.C-1 & C. gossypii var. cephalosporioides & Micoteca - Campinas SP \\
$02 \mathrm{c}$ & C.G.C-2 & C. gossypii var. cephalosporioides & Micoteca - Campina sSP \\
$03 \mathrm{c}$ & C.G.C. -3 & C. gossypii var. cephalosporioides & Micoteca - Campinas-SP \\
$04 \mathrm{c}$ & C.G.C-4 & C. gossypii var. cephalosporioides & Micoteca - Campinas-SP \\
$05 \mathrm{c}$ & C.G.C-5 & C. gossypii var. cephalosporioides & Micoteca - Campinas-SP \\
$06 \mathrm{c}$ & C.G.C-6 & C. gossypii var. cephalosporioides & Micoteca - Campinas-SP \\
$07 \mathrm{c}$ & A-4 & C. gossypii var. cephalosporioides & Uberaba-MG, gemas superbrotamento \\
$08 \mathrm{c}$ & A-11 & C. gossypii var. cephalosporioides & Uberaba-MG, gemas superbrotamento \\
$09 \mathrm{c}$ & A-13 & C. gossypii var. cephalosporioides & Uberaba-MG, gemas superbrotamento \\
$10 \mathrm{c}$ & A-42 & C. gossypii var. cephalosporioides & Uberaba-MG, gemas superbrotamento \\
$11 \mathrm{c}$ & B-4* & C. gossypii var. cephalosporioides & Uberaba-MG \\
$12 \mathrm{c}$ & P-15 & C. gossypii var. cephalosporioides & Lavras-MG \\
\hline
\end{tabular}

* apresenta reprodução sexual de forma espontânea 
Compatibilidade sexual e vegetativa do complexo Glomerella-Colletotrichum associado...

TABELA 2 - Tamanho médio $(\mu \mathrm{m})$ de conídios de Colletotrichum gossypii e Colletotrichum gossypii var. cephalosporioides em meio BDA, sete e 20 dias de cultura e percentagem de núcleos aos dez dias

\begin{tabular}{|c|c|c|c|c|c|c|}
\hline \multirow{3}{*}{ Isolado } & \multicolumn{4}{|c|}{ Dimensões dos esporos $(\mu \mathrm{m})$} & \multirow{2}{*}{\multicolumn{2}{|c|}{$\begin{array}{c}\% \text { de esporos com } 2 \text { ou mais núcleos } \\
10 \text { dias }\end{array}$}} \\
\hline & \multicolumn{2}{|c|}{7 dias } & \multicolumn{2}{|c|}{20 dias } & & \\
\hline & comprimento & largura & comprimento & largura & 2 núcleos & 3 núcleos \\
\hline 02 & $17,06 \pm 0,18$ & $7,31 \pm 0,42$ & $13,5 \pm 0,31$ & $5,18 \pm 0,01$ & 0,09 & - \\
\hline 04 & $13,60 \pm 0,18$ & $4,78 \pm 0,01$ & $15,05 \pm 0,2$ & $6,08 \pm 0,02$ & 0,16 & 0,02 \\
\hline $01 \mathrm{c}$ & $13,57 \pm 0,25$ & $5,05 \pm 0,01$ & $14,52 \pm 0,06$ & $5,03 \pm 0,13$ & 0,24 & 0,027 \\
\hline $02 \mathrm{c}$ & $13,79 \pm 0,22$ & $5,10 \pm 0,13$ & $13,79 \pm 0,26$ & $3,65 \pm 0,01$ & - & - \\
\hline $03 \mathrm{c}$ & $15,06 \pm 0,34$ & $4,37 \pm 0,01$ & $14,30 \pm 0,28$ & $4,88 \pm 0,01$ & 0,25 & - \\
\hline $07 \mathrm{c}$ & $15,91 \pm 0,24$ & $5,22 \pm 0,13$ & $16,38 \pm 0,18$ & $6,53 \pm 0,2$ & - & - \\
\hline $08 \mathrm{c}$ & $12,72 \pm 0,29$ & $3,73 \pm 0,01$ & $14,48 \pm 0,36$ & $4,71 \pm 0,01$ & 0,08 & - \\
\hline $09 \mathrm{c}$ & $13,04 \pm 0,14$ & $4,40 \pm 0,01$ & $14,78 \pm 0,30$ & $5,6 \pm 0,13$ & 0,79 & - \\
\hline $10 \mathrm{c}$ & $12,41 \pm 0,20$ & $4,74 \pm 0,13$ & $15,34 \pm 0,18$ & $5,21 \pm 0,3$ & 0,06 & - \\
\hline $\mathrm{CV}(\%)$ & 11,15 & 19,14 & 10,8 & 13,11 & - & - \\
\hline
\end{tabular}

a admitir que conídios multinucleados tenham se originado a partir de endomitoses. Conídios germinados foram encontrados em qualquer época da avaliação microscópica realizada. Isto revela um comportamento diferente ao de outras espécies do gênero Colletotrichum em que os autores relatam a presença de substâncias auto-inibidoras nos conídios (Mercer et al., 1975).

Foram também encontradas diferenciações celulares nas hifas com características de clamidósporos (Figura 1e-f). Medições do comprimento e diâmetro destas estruturas mostraram diferenças significativas entre e dentro de isolados $(P<0,005)$. Alguns isolados produzem mais clamidósporos do que outros, sendo encontrados com maior freqüência em $C . g$. var cephalosporioides (Tabela 3). Estas estruturas celulares podem ser de extrema importância em termos de sobrevivência e propagação do fungo, uma vez que esta espécie pode se manter viável em sementes por um período de até 13 anos (Stakman \& Harrar, 1957).

Os resultados de pareamento entre oito isolados (seis de $\mathrm{Cgc}$ e dois de $\mathrm{Cg}$ ) em placas de petri contendo meio BDA permitiram agrupar os isolados em três classes distintas de acordo com o grau de compatibilidade vegetativa e construir uma tabela classificando-os como compatíveis ou incompatíveis (Tabela 4).

No encontro compatível verificou-se a formação de setores fora da área de encontro (Figura 1g). Avaliando-se o efeito de repicagens das culturas verificou-se que as características fenotípicas dos setores foram mantidas ao longo das gerações.

A maioria das combinações enquadra-se no terceiro tipo descrito na metodologia, isto é, comportamento intermediário. Aos 20 dias, apenas duas combinações comportavamse como completamente incompatíveis (Figura 1h). Aos 40 dias, muitos isolados considerados incompatíveis aos 20 dias foram reagrupados como tolerantes, uma vez que houve um leve crescimento na região de encontro das colônias. Este padrão de crescimento pode ter ocorrido pela ação de alguma substância secretada, que provavelmente inibiu o crescimento ou causou morte celular, determinada pela incompatibilidade
TABELA 3 - Tamanho médio $(\mu \mathrm{m})$ de clamidósporos intercalares e terminais de Colletotrichum gossypii var. cephalosporioides em meio BDA/celofane aos dez dias de idade

\begin{tabular}{lccccc}
\hline \hline \multirow{2}{*}{ Isolado } & \multicolumn{2}{c}{ Intercalares } & & \multicolumn{2}{c}{ Terminais } \\
\cline { 2 - 3 } \cline { 5 - 6 } & Comprimento & Largura & & Comprimento & Largura \\
\hline 03 & $6,48 \pm 0,47$ & $5,65 \pm 0,37$ & & $13,44 \pm 0,66$ & $11,31 \pm 0,5$ \\
$04 \mathrm{c}$ & $10,40 \pm 0,85$ & $7,71 \pm 0,50$ & & $14,11 \pm 0,56$ & $12,47 \pm 0,48$ \\
$05 \mathrm{c}$ & $9,02 \pm 0,56$ & $6,44 \pm 0,40$ & & $7,69 \pm 0,51$ & $5,78 \pm 0,34$ \\
\hline CV (\%) & 30,37 & 25,47 & & 17,05 & 16,65 \\
\hline
\end{tabular}

$\mathrm{CV}=$ Coeficiente de variação da ANAVA realizada.

TABELA 4 - Reações de compatibilidade e incompatibilidade vegetativa dentro e entre os isolados de Colletotrichum gossypii $\mathrm{e}$ C. gossypii var.cephalosporioides. Avaliação aos 40 dias

\begin{tabular}{ccccccccc}
\hline \hline Isolado & $01 \mathrm{c}$ & $02 \mathrm{c}$ & $03 \mathrm{c}$ & $\mathbf{0 4 c}$ & $\mathbf{0 5 c}$ & $\mathbf{0 6 c}$ & $\mathbf{0 1}$ & $\mathbf{0 2}$ \\
\hline $\mathbf{0 1 c}$ & - & & & & & & & \\
$02 \mathrm{c}$ & - & - & & & & & & \\
$\mathbf{0 3 c}$ & - & - & - & & & & & \\
$\mathbf{0 4 c}$ & - & - & - & - & & & & \\
$\mathbf{0 5 c}$ & - & - & - & - & - & & & \\
$\mathbf{0 6 c}$ & - & - & - & - & - & - & & \\
$\mathbf{0 1}$ & - & - & - & - & - & + & - & \\
02 & - & - & - & - & - & - & + & - \\
\hline
\end{tabular}

(-): compatibilidade vegetativa; $(+)$ : incompatibilidade vegetativa

após o processo de anastomose. Com base nesta hipótese, foram agrupadas como tolerante ou incompatível após fusão (Leslie, 1993; Glass et al., 2000; Saupe, 2000). Ocorrência tanto de compatibilidade quanto incompatibilidade vegetativa já foi verificada dentro de uma mesma espécie (Cisaret al., 1994). Em Neurospora crassa Shear \& Dodge foram identificados genes de incompatibilidade vegetativa (Glass et al., 2000), o que ainda não ocorreu em Colletotrichum spp.

Pelos resultados, fica evidenciado que $C$. gossypii pode reproduzir-se sexuadamente, sendo uma espécie aparentemente homotálica. Os isolados apresentaram reação de incompa- 
M.G. Roca M. et al.

tibilidade vegetativa na presença de outros isolados do mesmo gênero permitindo a separação em grupos de compatibilidade ou incompatibilidade vegetativa somente, já que as características morfológicas avaliadas, ainda que mostrando diferenças estatisticamente significativas, não permitiram a diferenciação em grupos entre e dentro destas duas espécies.

\section{AGRADECIMENTOS}

À Dra. Renata Silva-Mann (Universidade Federal de Sergipe), pelas sugestões durante a realização do trabalho e preparo do manuscrito. Ao $\mathrm{CNPq}$ pelo auxilio financeiro e bolsas DTI e de IC.

\section{REFERÊNCIAS BIBLIOGRÁFICAS}

ALEXOPOUlOS, C.J., MIMS, C.W. \& BLACKWELL, M. Introductory Mycology. 4th ed. New York, John Wiley \& Sons, v.1, 1996.

ARONSON, B.D., JOHNSON, K.A., LOROS, J.J. \& DUNLAP, J.C. Negative feedback defining a circadian clock:auto regulation of the clock gene frequency. Science 263:1533-1656. 1994.

ATKINSON, G. F. Anthracnose of cotton. Journal of Mycologie 6:173-179. 1891.

CARLILE, M.J., WATKINSON, S.C. \& GOODAY, G.W. The fungi. San Diego. Academic Press. 2001.

CHACKO, R.J., WEIDEMANN, C.J., TEBEEST, C.G. \& CORRELL, J.C. The use of vegetative compatibility and heterokaryosis to determine potential asexual gene exchange in Colletotrichum gloeosporioides. Biological control 4:382-389. 1994.

CIA, E. \& SALGADO, C.L. Doenças do algodoeiro Gossypium spp. In: Kimati, H., Amorin, L., Bergamin F.A., Camargo, L.E.A. \& Resende, J.A.M. (Eds.) Manual de Fitopatologia, 3a ed. São Paulo. Agronômica Ceres, v. 2, 1997. pp.33-48.

CISAR, C.R., SPIEGEL, F.W., TEBEEST, D.O. \& TROUT, C. Evidence for mating between isolates of Colletotrichum gloeosporioides with different host specificities. Current Genetics 25:330-335. 1994.

CISAR, C.R. \& TEBEEST, D.O. Mating system of the filamentous ascomycetes, Glomerella cingulata. Current Genetics 35:127-133. 1999.

EDGERTON, C.W. The perfect stage of the cotton anthracnose. Mycologia 1:115-120. 1909.

GLASS, N.L., JACOBSEN, D. \& SHIU, P.K. The genetics of hyphal fusion and vegetative incompatibility in filamentous ascomycetes. Annual Review of Genetics 34:165-186 2000.

HICKEY, P.C., JACOBSON, D.J., READ, N.D. \& GLASS, N.L. Live-cell imaging of vegetative hyphal fusion in Neurospora crassa.
Fungal Genetics and Biology 37:109-119. 2002.

HORN, B.W., GREENE, R.L. \& DORNER, J.W. Inhibition of aflotoxin B-1 production by Aspergillus parasiticus using non aflatoxigenic strains:role of vegetative compatibility. Biological Control 17:147-154. 2000.

LESLIE, J.F. Fungal vegetative compatibility. Annual Review of Phytopathology 31:127-150. 1993.

MENDES-COSTA, M.C., DAVIDE, L.C. \& ROCA, M.G. Cytology of Colletotrichum lindemuthianum 'in vitro' (Sacc. \& Magn.) Scribner. Ciência e Agrotecnologia 22:250-253. 1998.

MERCER, P.C., WOOD, R.K., GREENWOOD, A.D. Ultrastructure of the parasitism of Phaseolus vulgaris by Colletotrichum lindemuthianum. Physiological Plant Pathology 4:203-214. 1975.

MAIELLO, J.M. Acervulus initiation in Colletotrichum capsici. Mycologia 80:410-413. 1988.

MOLNAR, A., SULYOK, L. \& HORNOK, L. Parasexual recombination between vegetative incompatible strains in Fusarium oxysporum. Mycological Research 94:393-398. 1990.

ROBERTSON, S.J., BOND, J. \& READ, N. Homothallism and heterothallism in Sordaria brevicollis. Mycological Research 102:1215-1223. 1998.

ROCA M., M.G. Aspectos citológicos da variabilidade genética em Glomerella cingulata (Stonem.) Spauld \& Schrenck f.sp. phaseoli (Colletotrichum lindemuthianum (Sacc. \& Magn) Scribner). (Dissertação de mestrado). Lavras. Universidade Federal de Lavras. 1997.

SACCARDO, P.A. Sylloge fungorum:omnium huius que cognitorum. Abellini:Typis Pergola. v. 22. 1944.

SAUPE, S.J. Molecular genetics of heterokaryon incompatibility in filamentous ascomycetes. Microbiology and Molecular Biology Reviews 64:489-502. 2000.

SILVA-MANN, R., CARVALHO, K.C.S., VIEIRA, M.G.G.C. \& MACHADO, J.C. Estudo da variabilidade genética de isolados do complexo Colletotrichum associados a sementes de algodão por meio de técnicas moleculares e inoculação em plantas. Fitopatologia Brasileira 27:27-32. 2002.

STAKMAN, E.C. \& HARRAR, J.G. Principles of Plant Pathology. New York. The Ronald Press. 1957.

SUTTON, B.C. The genus Glomerella and its anamorph Colletotrichum. In: Bailey, J.A. \& Jeger, M.J. (Eds.). Colletotrichum: biology, pathology and control. Wallingford. C.A.B. International. 1992. pp.1-26.

TANAKA, M.A., MENTEN M., J.O. \& MACHADO, J.C. Hábito de crescimento de Colletotrichum gossypii e C. gossypii var. cephalosporioides em sementes de algodoeiro. Bragantia 55:95-104. 1996.

TEBEEST, C.G., RILEY, L.H. \& WEIDEMANN, G.J. The number of nuclei in spores of three species of Colletotrichum. Mycologia 81:147-149. 1989. 
ERRATA publicada no Volume 29 Número 2 da revista

Por um lapso, na composição do Volume 29(1), a Figura 1(a, b,c, d, e, f, g, h), abaixo, do artigo "ROCA M., M.G., MACHADO, J.D.C., VIEIRA, M.G.C., DAVIDE, L.C. \& ROCHA, M.L. Compatibilidade Sexual e Vegetativa do Complexo Glomerella-Colletotrichum Associado a Sementes de Algodão. Fitopatologia Brasileira 29:16-20. 2004" foi omitida
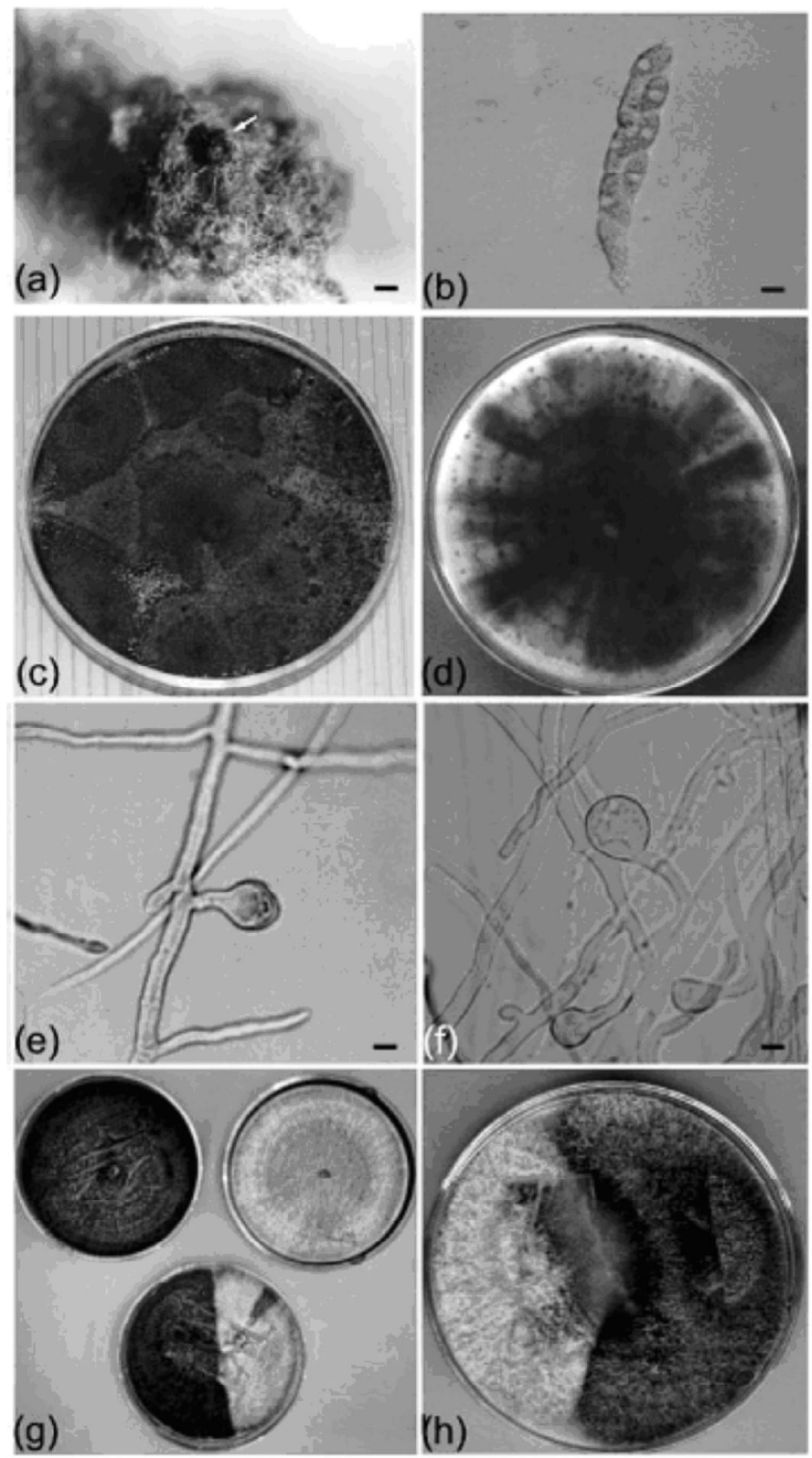

FIG. 1 - (a) Grupo de peritécios. Barra= 40 $\mu \mathrm{m}$; (b) Ascósporos em asca. Isolado 11c. Barra $=5 \mu \mathrm{m}$; (c) Isolado $11 \mathrm{c}$ iniciando peritécios em áreas de encontro com o isolado 05c em placa com BDA; (d) Placa mostrando anéis de acérvulos produzidos em intervalos iguais de tempo; (e) Clamidósporo terminal. Isolado 04c. Barra $=5 \mu \mathrm{m}$; (f) Clamidósporo intercalar. Isolado 04c. Barra $=5 \mu \mathrm{m} ;(\mathrm{g})$ Placa mostrando compatibilidade vegetativa e setor. Isolados 02 e $01 \mathrm{c} .40$ dias de cultura; (h) Placa mostrando incompatibilidade vegetativa. Isolados 02 e 01c. 40 dias de cultura. 